\title{
Western Media Influence on Emiratis Women National Identity
}

\author{
Hala El Saj \\ Holy Spirit University of Kaslik, Kaslik - Lebanon \\ hala_saj@hotmail.com \\ Charles M Sarraf \\ Holy Spirit University of Kaslik, Kaslik - Lebanon \\ charlessarraf@usek.edu.lb
}

Doi:10.5901/jesr.2014.v4n4p92

\begin{abstract}
In the last few years the expansion of modernism and globalization impact on different cultures has gained an importance among researchers. As borders have become increasingly porous as images; information and people are being exported with ease and speed across and beyond territorial boundaries. Thus as national boundaries have become increasingly permeable, susceptible to the outside influences of global information networks; this no doubt has an impact upon identities and communities sustained across space. This study examines the influence of the western media namely Oprah Winfrey show on Emirati working class women living in Abu Dhabi. This study explores the kind of Western programs consumed by these women, how these women perceive their national identity and to what extent their national identity is influenced by the media especially Oprah Winfrey show. The method adopted in this study is the multi-method approach using qualitative and quantitative methods in collecting data. The results showed that the Western talk shows are the most preferred programs among Abu Dhabi working women. A distinguishing attitude of belonging was expressed by all the participants asserting that they are proud to belong to the United Arab Emirates and proud to be Emirati. A concern and the feeling of a real danger was expressed by some participants regarding the modernization occurred in the country accompanied with the increase of expatriates number effecting the sense of nationalism among the locals. The study concluded that to some extent Oprah Winfrey has an impact on social and cultural thoughts among Abou Dhabi working class women, but did not succeed to have a significant influence on their national identity.
\end{abstract}

\section{Introduction}

Our mediated world has come to transcend the constraints of clock time and geographical location as communication and interaction now take place instantaneously between distant locations. However, the advent of modernity has changed this: sophisticated technological capabilities and more intense transnational communication networks have meant that space and place are no longer dependent on one another as relations now take place between 'absent' others and are not pre-conditioned by face-face interaction. Thus, as a consequence of modernity, Giddens (1990) highlights place to have become increasingly phantasmagoric, meaning that locales are now shaped in terms of social influences that may occur many miles away. Within this hyperspace, international media organizations are conveying images and representations to global audiences, making distant issues become events of local importance for local cultures.

Thus as national boundaries have become increasingly permeable, susceptible to the outside influences of global information networks; this no doubt has an impact upon identities and communities sustained across space (Georgiou, 2006, p.1). Georgiou (2006) focused specifically on the Greek-Cypriot diasporic community and how their sense of identity is shaped in the context of highly mediated everyday worlds. She highlighted how: "mediascapes...bring images of distant cultures close....they allow the re-appropriation of the distant in relation to the immediate, they represent and mediate meanings of localities, diasporas, homelands and communities" (Georgiou, 2006, p.12). Thus, the growing availability of communications technologies and on-going processes of media consumption have allowed a growing interconnection between distant locations, and increased interaction between disparate social groups. These patterns have become central factors in processes of identity construction for members of a global community.

In light of globalization, Steven Ross, asserts that the emergence of the new communication media will help transcend the differences between cultures and societies and to work towards a more genuine mutual trust and understanding (Morley \& Robin, 1995). On the contrary, internationalization through globalization makes the maintenance of national sovereignty and identity increasingly difficult as the composition of economic, cultural productions and consumption become increasingly transnational (Collins, Garnham \& Lockleys, 1987). 
Liebes \& Curran (1998) argue that the media plays a central role in our understanding of civil society. Media is not only regarded as a space where information is circulated so that citizens can be well-informed, but rather as a cultural space where actors and events become typified into more general codes and more generic story forms that resonate with the society's culture (Liebes \& Curran,1998). Crane (2002) argues that increasingly rapid dissemination of all types of media will pose problems for the maintenance of national identities as cultures undergo increasing hybridization.

As it is, the western media or more so the powerful and rich American media industry threatens the pluralism through massive flow of information, both ideologically and culturally laden from the West to the other countries. With it come ideas, attributes, images, issues, and agendas that may or may not be readily agreeable and acceptable within the local context. Consequently, it creates unrealistic hopes, expectations, and violations that if left unchecked will lead to a disruption of local norms (Servaes, 2006).

Among the Western media, Oprah Winfrey introduced as the most popular and famous television talk show, with millions of audience around the world. Oprah Winfrey's popularity in the Middle East has grown fast and it even exceeded her popularity in the USA ("Handbook: Satellite television in the Arab world", 2007). As Tim Riordan, director of group TV for MBC says, Winfrey draws an average audience of about 22 million each month across the Gulf, Levant and North Africa ("Handbook: Satellite television in the Arab world", 2007).

The show has become a common source of information and opinions about relationships, psychopathology and gender (Bhavnani \&Phoenix, 1994). They also describe the show as cultural icon that signifies at the same time "lurid dilemmas, emotional intensity, fame and black woman's success" (Bhavnani \& Phoenix, 1994, p.63). In terms of Middle East influence, several reporters have discussed the influence of Oprah on her Arab audience. Such as Octavia Nasr, CNN Arab Affair Editor, where Oprah is viewed as the face of success and her story inspires many women, particularly in the Arab world (Octavia, 2008. "Oprah" of Arabia. CNN News. October 31, 2008). Also an article published in New York Times, mentioning that some women in Dammam, (Saudi Arabia) say that Winfrey assures to her viewers "that no matter how restricted or even abusive their circumstances maybe, they can control ... and create lives of value [that] helps them find meaning in their cramped, veiled existence." They add that they are drawn to Winfrey "not only because she openly addresses subjects considered taboo locally, but also because she speaks of self-empowerment and change" (Zoepf, 2008. New York Times, Dammam journal, p.3). The Emirati National Conversation (2008) reports that "Emirati women are attracted to Oprah show precisely because it tackles issues no one in the society talks about." The article adds that "Oprah affects her viewers' language and their lifestyles" and that many in the UAE consider her as a role model, "not in her personal life, but in her attitude on issues" (Khagey, 2008).

In this study we sought to explore the influence of the media particularly Oprah Winfrey show on working class women in Abu Dhabi, addressing the following questions: which kind of programs is consumed by working class women in Abu Dhabi? How do working class women regard their national identity? To what extent did media particularly Oprah Winfrey show influence working class women's national identity?

\section{National Identity}

The national identity, as is directly related to individual and collective identity. Individual identity is defined as "a social identity that is shaped by certain characteristics as class, sex, and so forth, and refers to the individual level as distinct from ego-identity, which is different from how the individual is seen by society, but how it perceives itself "(Wodak et al., 2009, p.13). The individual identity is created by others and the individual itself and it relates to its present situation (Smith, 1991); it therefore is subject to change. A national individual identity is an identity in relation to someone in other nations that classify and are classified differently (Smith, 1991).

The social identity theory plays a more important role in understanding why people develop a national identity. If one belongs to a nation he/she is part of a certain social classification, for example, Arabian. It therefore allows an individual to identify itself with its social environment. It "is the perception of oneness with or belongingness to some human aggregate" (Ashford \& Meal, 1989, p.21). Another level of identity is the system related identity; "a collective identity not focused on the individual but rather on groups or sub-groups of society" (Wodak et al., 2009, p.16). As the individual is shaped by its individual and social identity, the nation is shaped and shapes the collective identity of its members (Ashmore, Jussim \&Wilder, 2001).

In the Emirati context, Kazim (2000) argues that the UAE's collective identity has been formed, to some degree, in relation to both the internal presence of a large expatriate population and in relation to the external forces of globalization. A key feature of politico-economy scene in the UAE is an ongoing dispute between those varied issues of globalization that wish on one hand to preserve the socio-cultural status based on oil economy, and on the other to argue for proglobalization policies that seek to liberalize and diversify the economy (as cited in Clarke, 2008, p.47). However, despite 
ongoing concerns about 'cultural contamination' particularly from the West, Davidson sees that UAE has a collective identity as constructed purely in reaction to perceived external threats (Davidson, 2005). The UAE is a 'willed nation' (Findlow, 2000) or an 'imagined community' (Anderson, 1983). Moreover, the basis for UAE collective identity lies partly in shared social norms and partly in the common partaking in shared economic success, as well as the shared social infrastructure (Davidson, 2005).

As Findlow (2000) notes, "the UAE government actively encourages active participation in building the country" (p.42), and it is reflected in cultural narratives of 'rags to riches' transition whereby a nation has been built out of nothing. "The resulting collective identity, reinforced through media and the education system, becomes self-reaffirming through repeated performance" (Findlow, 2000, p.43).

Besides national identity, according to Smith (1991), it is predominantly a spatial or territorial conception: "nations must possess compact, well defined territories. People and territory must, as it were, belong to each other...." (Smith, 1991, p.4). Thus, to feel part of a national community, citizens must share a common culture, ideology, a set of common understandings, ideas and aspirations that are all encapsulated within a well-marked geographical arena, uniting them with the sense of one joint homeland. Such a traditional conception of national identity is very much an inclusive definition underpinned by a need for geographical place. As Georgiou (2006) confirms: "once ethnicity was bounded, or forced to be bounded, in place. The ownership of specific bounded space was a key element for sustaining identity and community space" (Georgiou, 2006, p.2).

However, in addition to well-defined boundaries, national communities are also sustained by more abstract commonalities such as "historical memories, myths, symbols and traditions" (Smith, 1991, p.11) that are shared by a particular group of people. According to Choueiri (2000) "the Arab nation came in to being with the gradual elaboration of Arabic as a language of communication and the advent of Islam as a new culture and set of institutions" (Choueiri, 2000, p.23). A common language and shared religion, therefore, have united the dispersed peoples of this region into one joint community, and have constituted the cornerstone of their sense of a homeland. Although most Arab citizens have probably never had any contact with neighboring Arab nations, they feel united by the "myths, memories, symbols and values of Arab civilization, of which they feel a part of" (Choueiri, 2000, p.65).

\section{The Media, Nation-State and Local Identities}

Benedict Anderson's seminal work Imagined Communities, confirms how the need for common myths and symbols are the foundations that sustain any form of national belonging. Anderson's analysis adds an important dimension to the study of national identity that of the mass media (Anderson, 1991). As Smith (1991) suggested: "the task of ensuring a common public, mass culture has been handed over to the agencies of popular socialization," (Smith, 1991, p.11), and so in this sense, "sharing common media has advanced and underpinned a sense of belonging in a common project- that of the nation" (Georgiou, 2006, p.11). According to Anderson (1991) even though members of a nation will never know, hear of, or see fellow-members of their community "in the minds of each lives the image of their communion" (Anderson, 1991, p.6). This was made possible by the advent of the printing revolution that allowed readers speaking in various local dialects to understand each other, as newspapers and novels were printed in the same language (Georgiou, 2006).

In this light, the media, through their creation of a "shared symbolic space" (Silverstone,1994, p.98) that allowed others to engage in a "joint, public ritual," (Gillespie, 2000, p.167), helped epitomize the sense of a national consciousness. The television ever-present nature in our daily existence was pointed by Roger Silverstone (1994) who said: "how is it that such a technology and medium has found its way so profoundly and intimately into the fabric of our daily lives? How is it that it stays there?" (Silverstone ,1994, p. 2).

Thus, unlike other communications technologies, television has become so deeply embedded and entrenched in our daily routines, that it functions as "a kind of national calendar which organizes, coordinates and renews a national public social world" (Barker, 1997, p.134). Moreover, satellite broadcasting has made it possible for Arab women to witness developments and to follow the impacts of women's movements in different parts of the world as well as to watch the many transformations that have taken place in the Arab region (Killini, 1997). The multi-channel environment via satellite "is expanding the Arab viewer's choices of content without interference of governments" (Marghalani \& Boyd, 1998, p.297). The Middle East has many platforms competing for Arab viewers, Egyptian Radio and Television Union (ERTU) / Nile Channels, ART, Orbit Showtime Network (OSN), Star Select, Abu Dhabi TV, DubaiMedialnc (dmi), Middle East Broadcasting $(\mathrm{mbc}$ ) and others. All offer potential benefits to Arab women since they provide a lifeline to rural areas that terrestrial broadcast services do not reach and link the Arab household to the rest of the world (Amin, 2001).

As Anderson's analysis (1991) focuses on a specific historical period, we can give it more contemporary relevance by mentioning the changes that have come about with the advent of the information revolution: the development of 
modern and sophisticated communications channels mean the media's ability to sustain a sense of common identity across space has increased many folds. As Silverstone (1994) highlighted in today's media age, a "sense of identity and authenticity can be found not in the world of face-to-face relationships...but in the displacement of the real by the electronic and the virtual" (Silverstone, 1994, p.97). Today, the context is one of intense transnational interconnection rather than solely receiving symbols, myths and cultural images specific to their particular national community, people are exposed to foreign values and traditions from distant locations that invade their private sphere's via mass media outlets. As for

Amin (2001) who comes with a broad perception that satellite broadcasting represents "a form of cultural imperialism and a highly corrupting power of traditional values" (Amin, 2001, p.2). Harbi (1996) supported Amin and mentioned that the social impact of satellite viewing creates new and different manners and attitudes in the Arab world (Harbi, 1996, p.7).

A landmark study in this respect was David Morley's (1980) The Nationwide Audience, which attempted to investigate how the complex and divergent backgrounds of audiences who consume the current affairs program influences the meanings they give to it. Morley began by highlighting three positions that audiences can take in relation to an encoded message: the dominant code is where the audience takes the proposed meaning of the text fully, while with negotiated decoding, he/she takes the meaning broadly but can modify or partially inflect the given preferred meaning. The third position is an oppositional decoding where the audience brings to bear an alternative frame of reference which sets the encoded framework to one side (Morley, 1980, p.16). The results were quite 'path-breaking' as they demonstrated just how complex responses to the media can be (Morley, 1980). With respect to international television, this study demonstrated that the way audiences consume the media is a far from straightforward process: "Western news programs would be decoded by audiences according to their own cultural backgrounds in ways which would undercut the ideological effect of Western news within other cultures" (Baker, 1997, p.127).

\section{Research Methodology}

This study seeks to lay the basis for examining the influence of media (Oprah Winfrey show) on the national identity (sense of belonging) on working class women in Abu Dhabi (28 to 39 years of age). Given the lack of previous studies in the emirates, the current study can be considered as an important exploration of the dynamics of media in Abu Dhabi, and a beginning for future research.

Triangulation method is adopted in this study, defined as the combination of methodologies where the qualitative and quantitative methods should be viewed as complimentary rather than as rival camps (Jick ,1979). Each method is designed to answer different kinds of questions since the qualitative research involves analysis of data collected from interviews, observations, questionnaires, and so forth, while the quantitative method involves analysis of numerical data (Gay, 1996, p.11).

The quantitative component consisted of the use of 60 surveys. Originally 93 surveys were distributed among a sample of women employees and teachers across Abu Dhabi. In terms of age, the participants were relatively young, aged between 28 and 39. The level of education amongst the respondents was relatively high since all the participants hold Bachelor degrees.

To enhance reliability, unrealistic surveys that showed clear oppositions and inconsistencies, such as answers which users denied familiarity, were excluded. The qualitative component consisted of the use of a focus group session involving three focus groups (A-B-C) including six working class women per group. Group A consisted of six teachers aged between 28 and 31. Group B consisted of six employees working in Etisalat (Telecommunication Company) aged between 32 and 35 and group $C$ consisted of six bankers aged between 34 and 39 . Focus group participants also filled survey questionnaires. The session lasted one hour and a half. Upon their request, participants asked to remain anonymous. Focus group data is analyzed comparatively (Coomber, 1997) with survey data in the Results and Discussion section.

\section{Results and Discussion}

The introductory question was the choice of watching regularly a foreign talk show. As shown below, a strong majority $80 \%$ of participants answered that they watch Oprah Winfrey; it shows that Oprah's Show is the highest-rated Englishlanguage program watched among women, an age group that makes up about a third of UAE population. The second is the Doctors with $33 \%$ watching rate. We can notice the significant percentage difference between the first rate and the second rate of talk shows. 


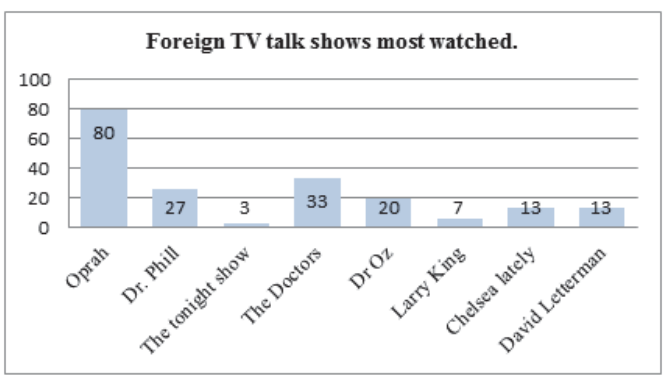

Table 1- Foreign TV talk show

In terms of the specific programs consumed, most focus group participants seemed to prefer ones that adopted Western programs such as talk shows and American movies preferring

Hollywood productions. The focus Group A participants, tend to prefer light entertainment programs such as Friends, Hell's Kitchen and Oprah Winfrey broadcast on the Arab regional channel MBC4. Group B highlighted how is their trend of watching Western programs that feature Arabic subtitles. They referred to The Drs and Oprah Winfrey as the most popular.

Group C participants had a strong and obvious trend towards news channels such as CNN, BBC and CNBC Arabiya on a regular basis.MBC4 was also mentioned referring to Oprah Winfrey show and Dr Phil. It appears, therefore, that satellite television is the most commonly viewed type of broadcasting amongst Emirati women, as Arab viewers watch more international satellite than Arabic satellite channels (Amin, 2001).

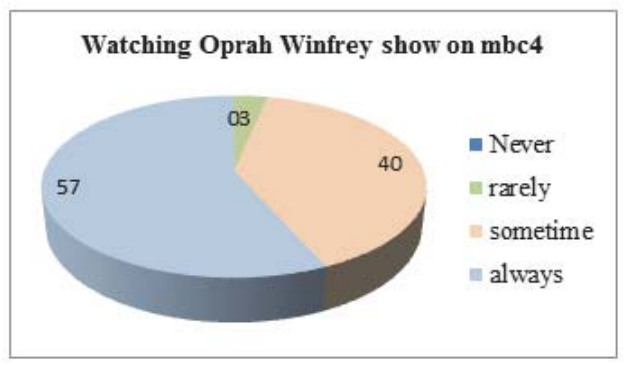

Table 2- Watching Oprah Winfrey show on mbc4

As indicated in the Pie Chart above, more than half of the participants $57 \%$ watch Oprah Winfrey, second rate of participants answered sometimes $40 \%$, rarely $3 \%$ and never $0 \%$. As it is shown the highest percentage provided by the majority of participants can represent that the female viewers try not to miss episodes from the show, it also represents the viewers' attachment to that show. Among the participants, no one answered that they never watch the show with $0 \%$.

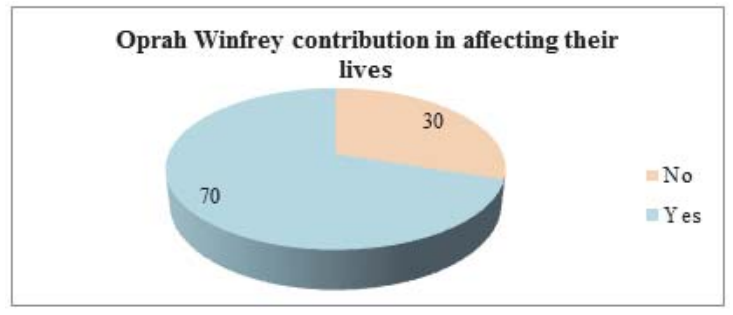

Table 3- Oprah Winfrey contribution in affecting their lives

Asking an important question about the contribution of Oprah Winfrey in affecting the participants 'life, as shown a strong 
majority $70 \%$ of the participants answered "Yes", $30 \%$ of the participants answered "No", Oprah did not contribute in affecting their lives. From the $70 \%$ of the answers derives different answers and different percentages. A significant percentage 24\% answered that Oprah contribute in changing their lives by being more effective and stronger. 19\% answered that Oprah guided them to solve several issues in their life and they wouldn't succeed without her guidance. $14 \%$ answered that Oprah changed their lives by making them changing their attitudes, and by giving them new ways of thinking about local taboos. And finally $13 \%$ of the participants stated that Oprah contribute in changing their lives through inspiring them to lose weight .Most focus groups participants agreed that Oprah definitely has a significant impact on her audiences. Group A suggested that Oprah influenced the language of her viewers; group B and C suggested that Oprah influenced the social activities and attitudes of her viewers as most of her female Arab viewers tries to change their actions according to her advices and invitations. Hence, group $\mathrm{C}$ stressed that these changes might be not applicable in their society; viewers should select what fits to their "entourage".

\subsection{National Identity and the Media}

Questioned about the factors that are the most influential regarding the sense of national identity, $73 \%$ of the participants respond social culture as well as $73 \%$ of the participants answered social values, which support the hypothesis of this paper. $57 \%$ of the participants answered language, $43 \%$ of the participants answered aspect of human behavior, as 33\% of the participants respond nation mind.27\% answered sense of belonging. Same percentage $13 \%$ was given by the participants regarding legal rights and Islamic religious beliefs. Finally, 10\% answered traits and 7\% answered ethnic. A majority of the participants think that social culture and the social values are the most elements influenced by the American culture as national identity can be summarized as sharing memories shapes and influences the values of a nation (Smith,1991).

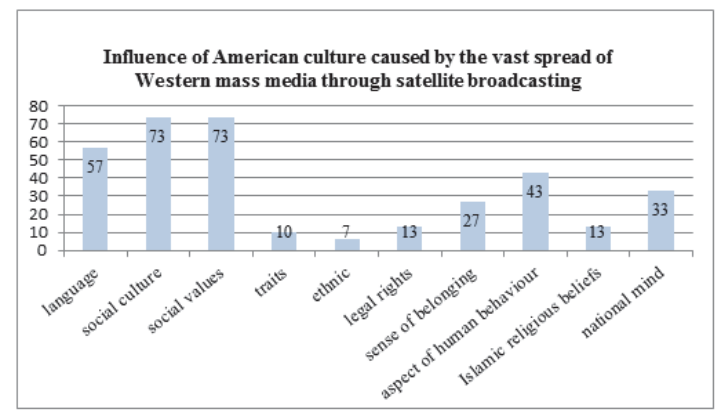

Table 4- Influence of American culture cause by the vast spread of Western mass media through satellite broadcasting

Participants of focus group A (aged between 28 and 31), agreed that the media in the UAE often played a negative role by emphasizing alien imported values instead of the indigenous culture. Group B participants (aged between 31 and 34) confirmed that the media caused Emiratis to become attached to a globally spreading Western culture at the expense of their own national identity. Participants of group C (aged between 34 and 39) adopt fundamentalist religious ideologies in expressing their opinions; giving a significant importance to the media influencing religion more than other cultural features. This group is the oldest among others, participants tried to constantly reinforce the fact that although they have been touched by aspects of Western culture, they are still able to maintain and observe the most sacred features of their identity. Additionally, they highlighted that those who consume Western media should have the ability to select what is suitable to their own cultural beliefs and ignore what contradicts it. 


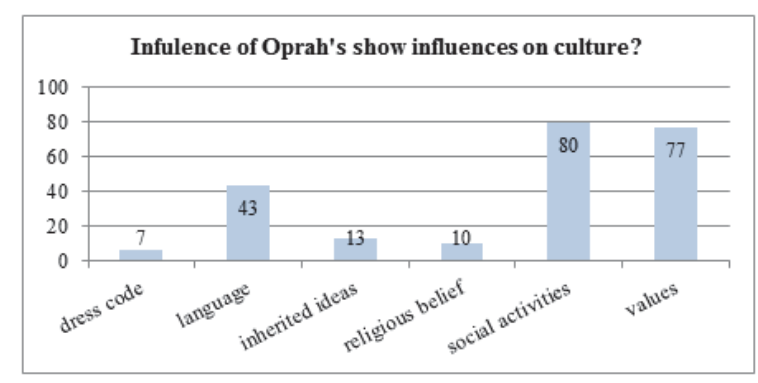

Table 5- Influence of Oprah's show on culture

When questioned regarding the influence of Oprah Winfrey on her audiences, a strong majority $80 \%$ of participants answered social activities, 77\% answered values, 43\% think that Oprah influence the language of her audiences,13\% think that Oprah influence the inherited ideas of her viewers, $10 \%$ answered religious belief and finally $7 \%$ answered dress code.

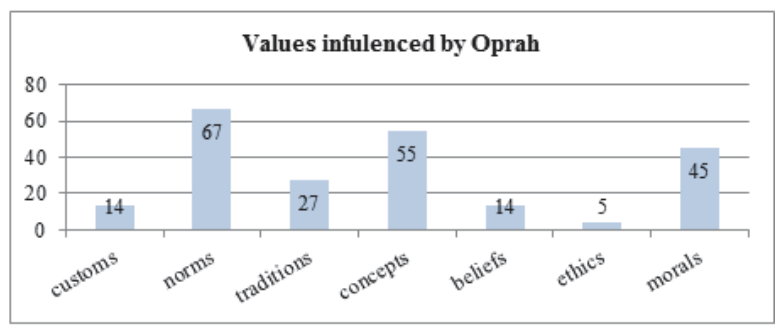

Table 6- Values influenced by Oprah

In an attempt to find which values have been influenced among the participants multiple choices were given. Results are as shown: a strong majority $67 \%$ responded norms, more than half of the participants $55 \%$ responded concepts, $45 \%$ morals, $27 \%$ traditions, and $14 \%$ answered customs and beliefs. Minority $5 \%$ of the participants answered ethics.

The influenced values vary among the groups. Group $A$ and $C$ value of education was influenced, as they were encouraged to get benefit from their educational achievements in social and familial ways, and looking forward to hold higher degrees. Group B, suggested that the value of work has been influenced as they seek for jobs and they desire working.

\section{Conclusion}

This study illustrated that United Arab Emirates as a society has experienced considerable western media. The most notable expansion has been in the broadcasting of Talk shows. The popularity of Oprah Winfrey show unveils an emerging of new social and cultural behaviors among working class women in Abu Dhabi. Oprah Winfrey did succeed in changing social thoughts, but did not have a significant influence on the working class women national identity. The sense of belonging was characterized as being so strong, but a sense of fear was revealed among the respondents, due to modernization and the increasing number of expatriates influencing the national sense of the locals. Suggesting that to preserve and shape the cultural identity of young Emirates and adults, efforts should be made to manage western media penetration.

\section{References}

Amin, H. (2001). Mass Media in the Arab States between Diversification and Stagnation. Mass Media, Politics and Society in the Middle East. Cresskill: Hampton Press.

Anderson, B. (1983). Imagined Communities: Reflections on the Origin and Spread of Nationalism. London: Verso.

Anderson, B. (1991). Imagined Communities: Reflections on the Origin and Spread of Nationalism. (revised and enlarged edition). 
London: Verso.

Ashford, B. E. \& Meal, F. (1989). Social Identity Theory and the Organization. Academy of Management Review 14, pp. 20 - 39.

Ashmore, B.E., Jussin, J., \& Wilder, W. (2001). Social identity, intergroup conflict, and conflict reduction. New York: Oxford University Press.

Barker, C. (1997). Global Television: An Introduction. Oxford: Blackwell Publishers.

Bhavnani, K., K. \& Phoenix, A. (1994). Shifting identities, shifting racisms: a feminism \& psychology reader. London: Sage.

Choueiri m Y. (2000). Arab Nationalism: A History, Nation and State in the Arab World. Oxford Malden, Mass: Blackwell Pub.

Clarke, M. (2008). Language teacher identities: Co-constructing discourse and community.UK: Cromwell Press.

Collins, R., N. Garnham \& G. Lockley (1987). The Economics of Television: The UK Case. London: Sage

Coomber, R. (1997). Using the Internet for Survey Research. Sociological Research Online. http://www.socresonline.org.uk/ socresonline/2/2/2.html.

Crane, D. 2002. Culture and Globalization: Theoretical Models and Emerging Trends. in D. Crane, N. Kawashima and K. Kawasaki (ed) Global Culture: Media, Arts, Policy and Globalization. New York. Routledge, pp. 1 - 25.

Davidson, C. (2005). The United Arab Emirates: A Study in Survival. Boulder, CO: Lynne Rienner. Decision Processes 51, pp.176-197.

Findlow, S. (2000). The United Arab Emirates: nationalism and Arab-Islamic identity Emirates. Center for Strategic Studies and Research (Abu Dhabi, ECSSR).

Gay, L.R. (1996). Educational research: competencies for analysis and application, $5^{\text {th }}$ Ed. New Jersey: Merrill.

Giddens, A. (1990). The Consequences of Modernity . Cambridge: Polity.

Gillespie, M. (2000). Ethnic Minorities and the Media. In Simon Cottle (ed). Ethnic Minorities and the Media: Changing Cultural Boundaries. Philadelphia: Open University Press.

Georgiou, M. (2006). Diaspora, Identity and the Media: Diasporic Transnationalism and Mediated Spatialities. Cresskill, N.J. : Hampton Press.

Harbi, M. (1996). The Sociological and Educational Impact of Satellite Dishes on High School Students. Journal of Education, number 26. Damiyetta: Egypt.

Jick, T. D. (1979). Mixing Qualitative and Quantitative Methods: Triangulation in Action. Administrative Science Quarterly, 24.

Kazim, A., (2000). The United Arab Emirates A.D. 600 to the Present: A Sociodiscursive Transformation in the Arabian. Gulf Book Center, Dubai.

Khagey, (2008). A Queen in the Kingdom. The Emirati National Conversation. Retrieved September 21, 2011, from http://www.thenational.ae/business/media/a-queen-inthe-kingdom.html.

Killini, S. (1997). Reflections of Satellite Viewing on the Traditional Sociological Trends of the Egyptian Youth. Journal of Arts and Human Sciences (Magallat al-Adaab wa al-Uluum al-Insaniyya), 25, Minya University.

Liebes, R. \& J. Curran, (1998). Media, ritual and identity. London: Routledge.

Marghalani, K., \& Boyd, D. (1998). The Utilization of Direct Satellite Broadcasting (DBS) in Saudi Arabia. Journal of Broadcasting and Electronic Media, volume 42, number 3.

Morley, D. (1980). The Nationwide Audience: Structure and Decoding. London: BFI.

Morley, D. \& K. Robin. (1995). Spaces and Identity: Global Media, Electronic Landscape and Cultural Boundaries. London: Routledge.

Octavia, N. (2008, October). Oprah" of Arabia.CNN News. Retrieved July 18, 2011, from http://ac360.blogs.cnn.com/2008/10/31/

Serveas, J. 2006. Constructing Cultural Identity Locally. China Media Research 2(3).

Schlesinger, P. (1991). Media, State and Nation: Political Violence and Collective Identities. London: Sage Publications.

Silverstone, R. (1994). Television and Everyday Life. London: Routledge.

Smith, A. D. (1991). National Identity. London: Penguine Books.

Dishing Democracy - Handbook: Satellite Television in the Arab World (2007). Wide Angle. http://www.pbs.org/wnet/windeangle/ episodes/dishing-democracy/handbook-satellite.

Wodak, R., de Cillia, R., Reisigl, M. Liebhart, K. (2009). The Discursive Construction of National Identity (2nd ed.). Edinburgh: Edinburgh University Press.

Zoepf, K. (2008, September). Saudi Women Find an Unlikely Role Model: Oprah. Dammam Journal. New York Times, 3. Retrieved July 8, 2011, from http://www.nytimes.com/2008/09/19/world/africa/19iht-19oprah.16293787.html 